\title{
Performance explorations of single chamber microbial fuel cells by using various microelectrodes applied to biocathodes
}

\author{
Edoardo Guerrini ${ }^{a}$, Matteo Grattieri ${ }^{b}$, Stefano P. Trasatti ${ }^{a}$, \\ Massimiliano Bestetti ${ }^{b}$, Pierangela Cristiani ${ }^{c, *}$ \\ a Department of Chemistry, Università degli Studi di Milano, Via Golgi 19, 20133 Milan, Italy \\ ${ }^{\mathrm{b}}$ Department of Chemistry, Materials and Chemical Engineering, Politecnico di Milano, Piazza Leonardo Da Vinci, 32, \\ 20133 Milan, Italy \\ c RSE - Ricerca sul Sistema Energetico S.p.A, Sustainable Development and Energy Sources Department, 20133 \\ Milan, Italy
}

\section{A R T I C L E I N F O}

Article history:

Available online 17 July 2014

Keywords:

Biofilm

Biocathode

Microelectrodes

Microbial fuel cells

\begin{abstract}
A B S T R A C T
Correlations among biofilm activity, chemistry and power production of membraneless, single chamber microbial fuel cells (MFC) were established using four microelectrodes. Each different $\left(\mathrm{pH}\right.$, redox, conductivity, $\mathrm{S}^{-2}$ ) microelectrode was assembled, calibrated and located close to the cathode.

Power productivity of five MFCs was explained in terms of response of the microelectrodes. $\mathrm{pH}$ variation demonstrated that a proton gradient establishes within the cathodic biofilm, increasing acidity near the electrode. Conductivity increases inside the biofilm, proving low diffusion and increased ion concentration. Redox profiles provide a significant improvement to the understanding of the biochemical equilibria inside and outside the biofilm. Sulphide variations emphasize the role of the sulphur cycle in the MFC development. Diffusion hindrance seems the key-factor for the development of a biofilm and the establishment of a natural separation of the cell in cathodic and anodic compartments. Copyright $\odot$ 2014, Hydrogen Energy Publications, LLC. Published by Elsevier Ltd. All rights
\end{abstract}

reserved.

\section{Introduction}

World interest in renewable energies strongly supports research of new sources, such as simple and cost effective Microbial Fuel Cells (MFCs). This relatively new technology explores the possibility of obtaining electricity from microbial digestion of organic substances at the anode [1-3] and the contemporary microbial reduction of inorganic compounds $\left(\mathrm{O}_{2}, \mathrm{NO}_{3}^{-}, \mathrm{SO}_{4}^{-2}\right.$, etc. $)$ at the cathode, with simultaneous flow of electrons through an external circuit $[4,5]$. In a membraneless MFC, the same microbial communities may colonize both anode and cathode and a multitude of chemical substances are potentially involved in the bio-electrochemical processes catalyzing the current flow $[6,7]$.

\footnotetext{
* Corresponding author.

E-mail addresses: Edoardo.guerrini@unimi.it (E. Guerrini), Matteo.grattieri@polimi.it (M. Grattieri), stefano.trasatti@unimi.it (S.P. Trasatti), massimiliano.bestetti@polimi.it (M. Bestetti), Pierangela.Cristiani@rse-web.it (P. Cristiani). http://dx.doi.org/10.1016/j.ijhydene.2014.06.132

0360-3199/Copyright @ 2014, Hydrogen Energy Publications, LLC. Published by Elsevier Ltd. All rights reserved.
} 
The simplified structure of the membraneless (single chamber) MFC may offer great advantage in term of costs. Therefore, the mechanisms of the (bio) electrochemical/(bio) chemical reactions that occur at the electrode interface and in the solution deserve to be exhaustively investigated. The use of microelectrodes could help to reach the goal.

Microelectrodes of various dimensions and purpose were successfully applied in the past, in fields different from MFCs, to study the activity of microbial communities and biofilm metabolism [8-11].

The electro-activity of cathodic and anodic biofilms causing microbial corrosion of metals was also industrially exploited in electrochemical sensors, despite the involved electrochemical mechanism has not yet been exhaustively clarified [12,13].

More recent works demonstrated the great potentiality of using three-electrodes compact microcells for the analysis of different parameters inside anodic biofilms. Nevertheless, to the best of our knowledge, measurements were performed mostly for two chamber microbial fuel cells and only on anode biofilms. Microelectrodes and microcells were used to measure $\mathrm{pH}$ and redox potential [14] or flavin concentration [15], via potentiometric and square-wave voltammetric methods. Due to their compact design, those microcells are suitable for studying living biofilms on polarized surfaces. Physicochemical parameters variation was demonstrated up to a few hundreds of micrometers from the anode surface using biofilms appositely grown under potentiostatic polarization, in a deareated (by nitrogen gas) feeding solution $[14,16]$.

Recent studies $[17,18]$ recognized that microbes like Sulphate Reducing Bacteria (SRB) can settle on the water side of an open air biocathode of single chamber MFCs [19] using sulphur as cyclic carrier of electrons to oxygen, in synergy with the process of direct oxygen reduction to water. The concomitant direct and mediated oxygen reduction permits the development of fully operative membraneless MFCs, although both cathode and anode are exposed to the same initial microbial pool.

In the present work, the role of the cathodic electro-active biofilm in membraneless single chamber MFCs is investigated using four home-made microelectrodes: $\mathrm{pH}$, sulphur concentration, conductivity and redox potential. Size, shape and placement of the electrodes were defined to reach cathode recessed locations. Construction, calibration and suitability of the four different types of microelectrodes are discussed.

The above parameters were chosen because expected to have relevant influence on the MFC performance.

\section{Experimental}

\section{MFC setup}

A Pyrex bottle of $125 \mathrm{~mL}$ was equipped with a large Pyrex flange on one side, to accommodate the open-air cathode. Two smaller openings were present on the opposite side. One of the openings was used as inlet to insert the anode. On top of the bottle, a hermetic plastic screw cap was used to prevent contact of the electrolyte with air (Fig. 1A).

Wastewater effluent collected from a digestate of a biogas plant was used as medium and natural inoculum of the MFCs. The digestate is characterized by strong $\mathrm{pH}$ buffering power (pH typically around 8.4), initial high COD (Chemical Oxygen Demand, up to $2000 \mathrm{mg} \mathrm{L}^{-1}$ of $\mathrm{O}_{2}$ ) and low BOD (Biological Oxygen Demand). Sodium acetate was then used as fuel for bacterial metabolism to reach a concentration of $3 \mathrm{~g} \mathrm{~L}^{-1}$ at the beginning of each experiment. During experiments, sodium acetate was periodically added as a marked decrease of the power productivity was evident ( $3 \mathrm{~g} \mathrm{~L}^{-1}$ doses).

Anodes were made of $2 \times 5 \mathrm{~cm}$ carbon cloth (SAATI C1), without any pre-treatment or additional layers on the surface. Carbon cloth was electrically connected to a plastic-insulated copper wire by a carbon-based conductive paste (TIMCAL LiQuid 101). The connection was insulated by at least 5 layers of high-viscosity epoxy resin (MAPEI Epojet). The anode was mounted in the lower opening by a rubber plug. Electrical connection was tested for internal resistance and fluid contact/leakage by prolonged exposure to distilled water.

Cathodes were $3 \times 3 \mathrm{~cm}$ carbon cloth (SAATI C1) obtained with the procedure described in Ref. [20] by the addition of: a) one layer of carbon (TIMCAL ENSACO 350G) + Nafion ${ }^{\circledR}$ ink on

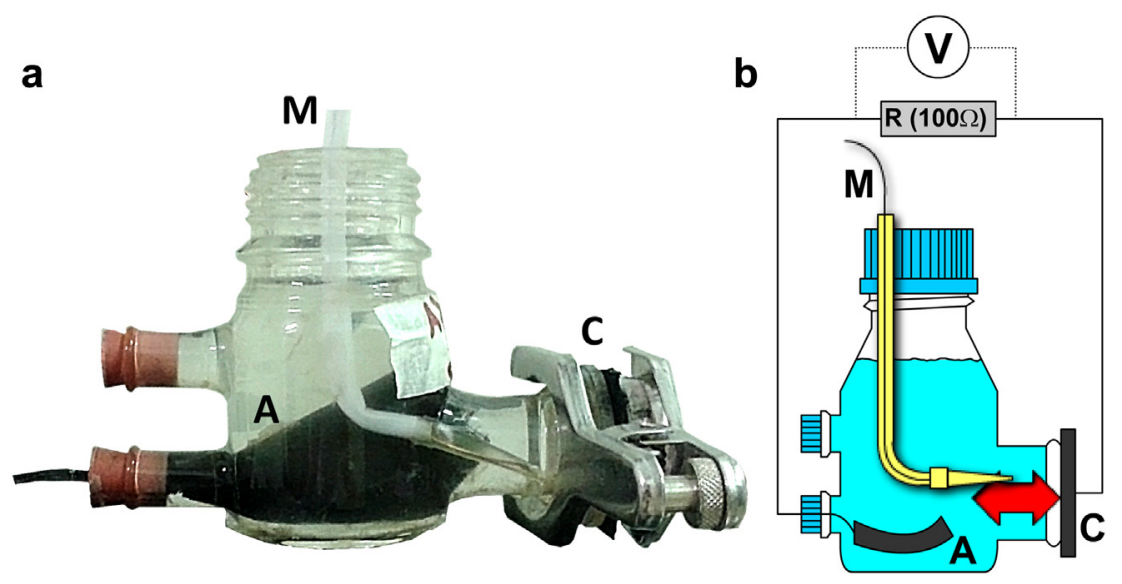

Fig. 1 - Images of a single chamber MFC: a) image of the glass cell, equipped with electrodes and microelectrode; b) sketch of the experimental equipment with the electrical connections to the voltmeter and to the external resistance $\mathrm{R}$. (A = Anode; C = Cathode; $\mathbf{M}=$ Microelectrode). 
the internal surface (Micro Porous Layer, MPL and b) one layer of carbon (TIMCAL ENSACO 350G) + Teflon $^{\circledR}$ ink on the external surface (Gas Diffusion Layer, GDL, in contact with air). The geometrical surface area exposed to the solution was a circle with a diameter of $2 \mathrm{~cm}$.

Two sets of MFCs were used, as described in Table 1. The difference was only the composition of the external (GDL) layer of the cathode. One type of cathode had a GDL containing carbon powder (TIMCAL ENSACO 350G) and 140\% $\%_{\mathrm{w} / \mathrm{w}}$ Teflon ${ }^{\circledR}$. The other type was prepared utilizing carbon powder (TIMCAL ENSACO 350G) and $80 \%$ w/w Teflon $^{\circledR}$. The cathode was connected (Fig. 1B) to the anode via an external resistance $(R=100 \Omega$, Fig. 1B). All experiments were performed in a thermostated chamber at $25 \pm 3{ }^{\circ} \mathrm{C}$.

\section{Microsensors construction and calibration}

All electrochemical microsensors were built by embedding metallic wires in micropipette tips using epoxy resin (MAPEI Epojet). The edge of the tip was polished with fine emery paper (1200 grit). Exposed metallic surface was electrochemically cleaned via repeated galvanostatic hydrogen/oxygen alternate evolution. The tip was then mounted on a Teflon tube and mechanically bent as needed for in-vivo measurements (Fig. 2).

Finally, the unmasked metallic surface was modified in agreement with established procedures available in the open literature and specific for each type of sensor.

\section{Redox microsensor}

The redox sensor was a potentiometric-type, Pt-based sensor, according to the procedure described in Refs. [21,22]. It consisted of a Pt wire (Goodfellow, 99,99\%, diameter of $50 \mu \mathrm{m}$ ) electrically connected by an electro-welded copper wire. The interstice between the platinum wire and the micropipette was filled up with epoxy resin to prevent any electrical leakage. The appearance of the tip is shown in Fig. 3A.The redox measurements were performed by directly dipping the as-embedded Pt microelectrode in the test solution.

\section{Conductivity microsensor}

A conductivity cell normally consists of two parallel plates of platinized Platinum (high surface area platinum black) at a fixed distance. This design ensures linearity of the electrochemical answer and avoids polarization effects in the ionic double layer at the electrode surface. The conductivity microsensor was built by coating separately two Pt wires (Goodfellow, 99,99\%, $50 \mu \mathrm{m}$ diameter) with epoxy resin

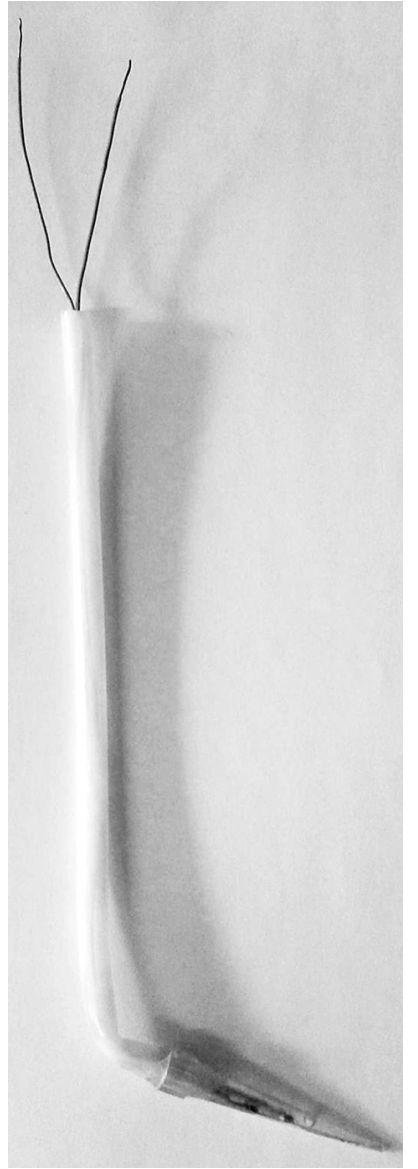

Fig. 2 - Particular of the microsensor for conductivity measurements, with the two metallic wires and the bent tip to approach the cathode.

(insulator). After curing, the two wires were embedded in the micropipette tip by using the same resin. The tip was polished as above reported. The exposed surface is shown in Fig. 1B. Actually, the two Pt surfaces are not parallel as they should ideally be, while the metal surface is smooth and coplanar. Therefore, signal saturation and strong matrix effects can affect measurement. Calibration against a commercial conductivity cell was attempted. Monotonic response was obtained: as the conductivity of the calibration solution was increased by $\mathrm{KCl}$ addition, an increased signal was obtained from the micro conductivity cell. Although no direct correlation was found between the actual conductivity and the

Table 1 - : MFCs setup and denomination.

\begin{tabular}{|c|c|c|c|c|}
\hline MFC & Anode & Cathode & Cathode & Cathode \\
\hline Denomination & Material $^{\mathrm{a}}$ & Base material $^{a}$ & $\mathrm{MPL}^{\mathrm{b}}$ & $\mathrm{GDL}^{\mathrm{b}}$ \\
\hline A1 & CC & CC & $C+40 \%$ Nafion & C $+80 \%$ Nafion \\
\hline A2 & CC & CC & $C+40 \%$ Nafion & C $+80 \%$ Nafion \\
\hline B1 & CC & $\mathrm{CC}$ & $C+40 \%$ Nafion & $C+140 \%$ Nafion \\
\hline B2 & CC & CC & $C+40 \%$ Nafion & $C+140 \%$ Nafion \\
\hline B3 & CC & CC & $C+40 \%$ Nafion & $C+140 \%$ Nafion \\
\hline
\end{tabular}

${ }^{a}$ CC: Carbon Cloth SAATI C1.

b C: Carbon Powder TIMCAL ENSACO 350G. 

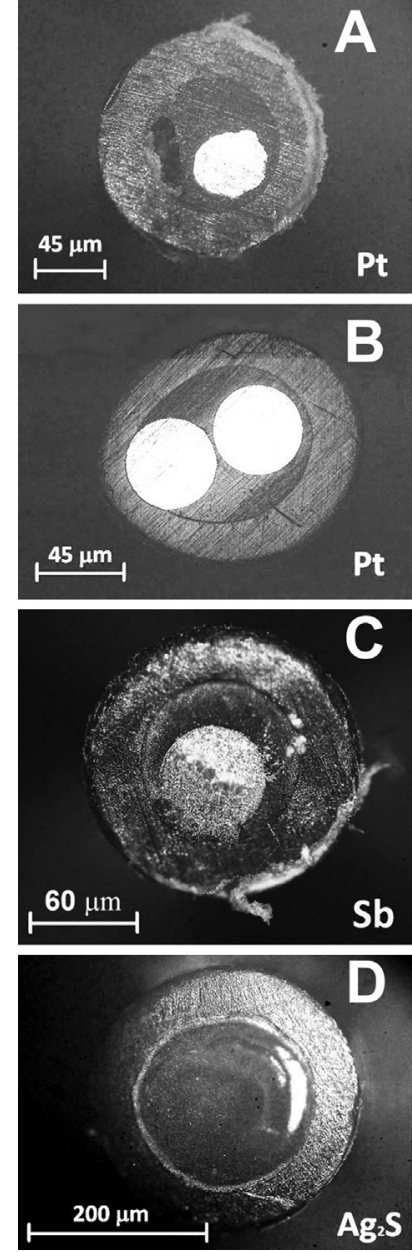

Fig. 3 - Optical images of the tips of: A) the redox microsensor; $\mathrm{B}$ ) the conductivity microsensor; C) the $\mathrm{pH}$ microsensor with $\mathrm{Sb}$ oxide layer; $\mathrm{D})$ sulphide microsensor with $\mathrm{Ag}_{2} \mathrm{~S}$ ad-layer.

measured signal, the response of the microsensor qualitatively corresponded to the trend of the actual conductivity. Therefore, measured conductivities have been expressed in arbitrary units.

\section{pH microsensor}

Commercial pH "microsensors" have sensing diameters in the millimeter range. It was chosen to build a pH microsensor from a gold wire (Goodfellow, 99,99\%, annealed. $50 \mu \mathrm{m}$ diameter), coated with a thin layer of $\mathrm{Sb}_{2} \mathrm{O}_{3}$. (Fig. 1C). Electrodeposition of antimony oxide was carried out in a solution of $\mathrm{SbCl}_{3}$ (0.05 $\mathrm{M} \mathrm{SbCl}_{3}, 0.2 \mathrm{M}$ tartaric acid, $0.1 \mathrm{M}$ Nitric acid) [23]. Pulsed square wave galvanostatic electrodeposition was performed ( $1 \mathrm{~s}$ at $-3 \mathrm{~A} \mathrm{~cm}^{-2}, 9 \mathrm{~s}$ at cell-off). At the end of the electrodeposition, the microsensor tip was repeatedly rinsed with distilled water. A layer of Nafion was deposited on $\mathrm{Sb}$ oxide to increase the selectivity and durability of the microsensor [24], and to decrease the possible influence of solution redox potential.

Calibration of $\mathrm{pH}$ microsensors (Fig. 4A) was performed in distilled water on different days just to check the stability of the sensor with time. As a matrix effect was observed while
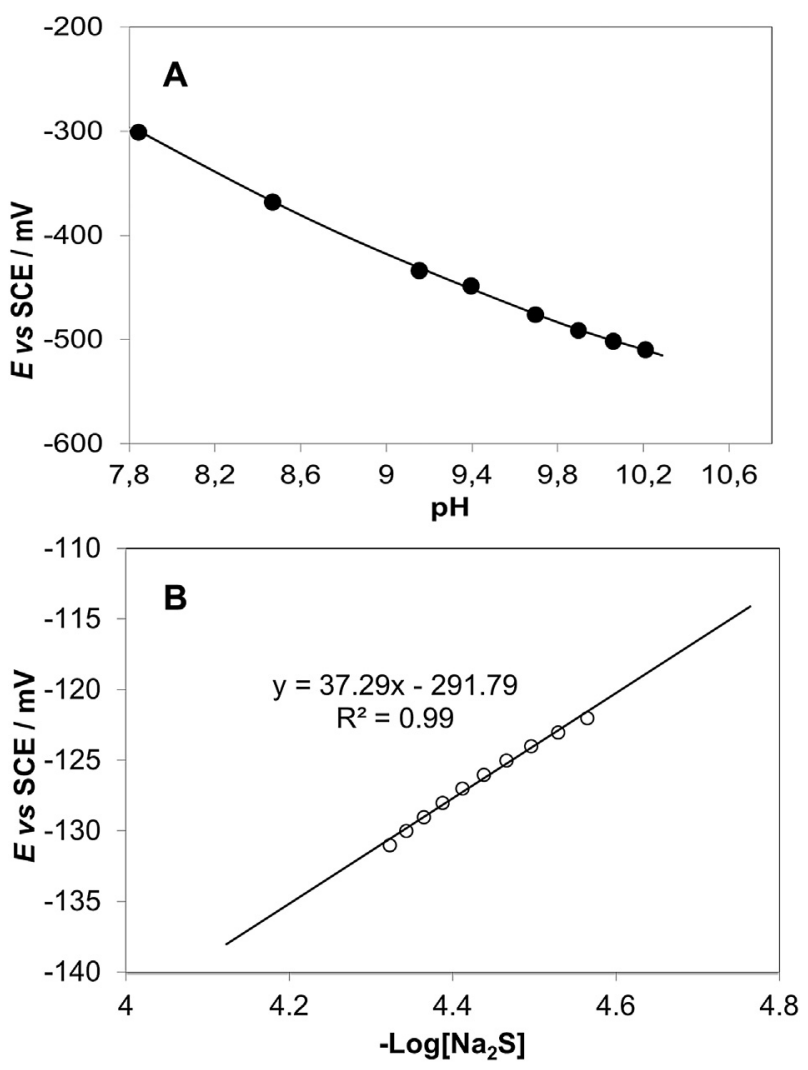

Fig. 4 - Calibration graphs of two microsensors: A) pH microsensor, with the experimental points $(0)$ and the interpolated second-order polynomial (solid line); B) Sulphide microsensor, with experimental points $(\bigcirc)$ and the interpolation linear regression.

calibrating in wastewater solution, a Nafion layer was deposited by adsorption on the $\mathrm{Sb}_{2} \mathrm{O}_{3}$ coating. This procedure allowed pH microsensors to be stable for at least two weeks. It is known that $\mathrm{Sb}$ oxide microsensors are stable in a limited $\mathrm{pH}$ range, approximately between $\mathrm{pH} 5$ and 11 (although different ranges are reported in the literature, depending on the preparation method [23]). The calibration $\mathrm{pH}$ was chosen in this interval. pHs outside this range could damage the microsensor. As a matter of fact, a pH between 5 and 11 is typical of solution bulk, as reported in a previous work with the same type of MFCs [25]. Interpolation of the calibration curves by linear regression around $\mathrm{pH} 8$, gave a slope of $56.5 \pm 4.5 \mathrm{mV}$. The need for extending measurement down to $\mathrm{pH} \sim 6$, forced us to use a calibration interpolation with a 2nd order polynomial function, since the calibration plot was not linear in such wide range of $\mathrm{pH}$.

\section{Sulphide microsensor}

A wire of Ag (Goodfellow, 99,99\%, diameter of $200 \mu \mathrm{m}$ ) was welded to a copper wire and embedded as above reported. The $\mathrm{S}^{-2}$ microelectrode was then constructed following the experimental procedure described in Refs. [26,27]. A layer of $\mathrm{Ag}_{2} \mathrm{~S}$ was electrochemically grown on the surface of $\mathrm{Ag}$ by constant potential electro-erosion in a saturated $\mathrm{Na}_{2} \mathrm{~S}$ solution with a three-electrode configuration. The working potential was $480 \mathrm{mV}$ (vs. SCE), according to Eftekhari and 
Zhejiang $[26,27] . \mathrm{Ag}_{2} \mathrm{~S}$ is highly insoluble in water $\left(\mathrm{ks} \cong 10^{-50}\right)$, and the solubility equilibrium depending on the $\mathrm{S}^{-2}$ concentration. The optical microscope image of the $\mathrm{Ag}_{2} \mathrm{~S} / \mathrm{Ag}$ surface is shown in Fig. 3D. Calibration of the microsensor was carried out by measuring its electrode potential (vs. SCE) in a solution at different $\mathrm{S}^{2-}$ concentrations, using $337 \mathrm{Amel} \mathrm{mV/pH-meter}$ and the standard additions method of $0.1 \mathrm{M} \mathrm{Na}_{2} \mathrm{~S}$. A typical calibration curve is reported in Fig. $4 \mathrm{~B}$, showing an average slope, the first day, of about $37 \mathrm{mV}$ (a value slightly higher than the theoretical $30 \mathrm{mV}$ ). Linear plots are obtained in very narrow concentration intervals. With aging (days), slopes remain unchanged, but the line is shifted and the intercept changes. Accordingly, calibration was performed each day just prior to in-cell measurements.

\section{Electrochemical measurements}

Power calculation

Several possible sources of measurement inaccuracy might arise in a complex and manifold system like microbial fuel cells. The first scrutinized parameter is the electrical power generated by each MFC.

Electrons flowing from the anode to the cathode generate an electric current (I) at a potential difference (E) across an electrical resistance $(R)$ of $100 \Omega$. E was recorded every $10 \mathrm{~min}$, using a multichannel Data Logger (Graphtec midi LOGGER GL820). The generated power (P) was calculated by the equation $P=E \cdot I=E^{2} / R$ and the power density was obtained by normalizing it to the geometric surface area $\left(\mathrm{m}^{2}\right)$ of the cathode.

\section{Microelectrode measurements}

Microelectrode measurements were conducted using a manual XYZ micromanipulator. MFCs were fixed on the translation stage and the microsensors were immersed in the cell solution and positioned at a given initial distance from the cathode surface. Due to the design of MFCs, accessible distances from the cathode were in the range $0-20 \mathrm{~mm}$. The signal at $20 \mathrm{~mm}$ was taken as representative of the bulk solution. The manual stage allowed movements in steps of at least $100 \mu \mathrm{m}$.

All measurements were conducted under open circuit conditions by disconnecting the electric resistance. As no net current flows and no chemicals are directly formed on the electrode surface, it is reasonable to consider the diffusion contribution of electrochemically producing species negligible.

Redox microsensor measurements were obtained as the potential difference between a commercial saturated calomel reference electrode (SCE, $+224 \mathrm{mV}$ vs. $\mathrm{RHE}$ ) and the Pt redox sensor. The potential difference was measured by a highinternal-resistance voltmeter (337 Amel mV/pH-meter). Measured values are mixed redox potentials, as a result of the potentials of all active redox-couples in the solution. It is known that redox couples not reacting on a Pt electrode (irreversible couples and/or kinetically hindered reactions, like most organic compounds), are unable to equilibrate with the Pt surface [22] These couples do not establish a unique redox potential on $\mathrm{Pt}$ and do not contribute to the measured potential. Accordingly, independently of the nature of the electroactive redox couples, the value of the measured redox potential is the result of changes in the sole Pt-affine redox couples. Redox microsensors cannot be applied for the analytical detection of single compounds, which is not the aim of the present paper.

The conductivity microsensor showed difficulties to obtain of a calibration curve and in turn a real micro-conductivity profile. Nonetheless, monotonic increase of the signal with increasing conductivity of calibrating solutions allows to carry out comparative evaluations of conductivity variations inside MFCs. The value of the microelectrode conductivity is therefore reported as-measured, in arbitrary-units.

The $\mathrm{pH}$ microsensor is based on the capability of some electron-conducting transition metal oxides (Sb, Ir, Ru, Co, etc.) to change their surface charge, as a function of the concentration of $\mathrm{H}^{+}$ions in solution. For these oxides, $\mathrm{H}^{+}$ions act as potential-determining-ions (pdi). Adsorption (or chemical reaction) of $\mathrm{H}^{+}$with oxygen atoms from oxide lattice modifies the surface charge of the electrode and in turn the potential of the conducting matrix, as exemplified by the following reaction:

$\mathrm{MO}_{x} \mathrm{H}_{y}+a \mathrm{H}^{+} \rightarrow \mathrm{MO}_{x} \mathrm{H}_{y+a}^{a+}$

where $\mathrm{M}$ is the metal atom on the solid oxide surface, and $a$ is the number of protons exchanged. The uptake of protons is reversible and potential changes have Nernstian-like dependence on $\mathrm{pH}$. Calibration of the sensor in this work was performed by determining an experimental curve, correlating the microsensor signal $(\mathrm{mV})$ with the actual $\mathrm{pH}$ of a solution as measured with a standard glass electrode (Metrohm 6.0262.100 Ecotrode Plus). Solution pH was modified with the standard additions method. The interpolation function is a second order polynomial $\left(\mathrm{pH}=a \mathrm{x}^{2}+\mathrm{bx}+\mathrm{c}\right.$, where $\mathrm{x}$ is the microelectrode signal, solid line in Fig. 4A), from which it is possible to obtain the $\mathrm{pH}$ of unknown samples.

Sulphide $\left(\mathrm{S}^{-2}\right)$ measurements were performed by dipping the $\mathrm{Ag}_{2} \mathrm{~S}$-based microsensor in the testing solutions and recording its potential against a reference electrode (SCE). The sulphide concentration was achieved by calculation from calibration plots.

\section{Results and discussion}

\section{Power production trends}

The potential difference across an external resistance of 100 ohm was recorded for at least 25 days of MFC operation. Power density vs. time plots are reported in Fig. 5. Black triangles ( $\mathbf{\Delta})$ on the abscissa represent the additions of $3 \mathrm{~g} \mathrm{~L}^{-1}$ of acetate to the cells.

MFCs start with no power production until a rapid increase is observed. The time at which the increase occurs, depends on the MFC type. A1 and A2 reach a rather stable maximum within three days. Then, the power decreases quickly down to zero as acetate is consumed [17]. As acetate is supplied again, power returns to a maximum value. A1 and A2 MFCs develop prompt and stable power density in the range $300-500 \mathrm{~mW} \mathrm{~m}^{-2}$. 


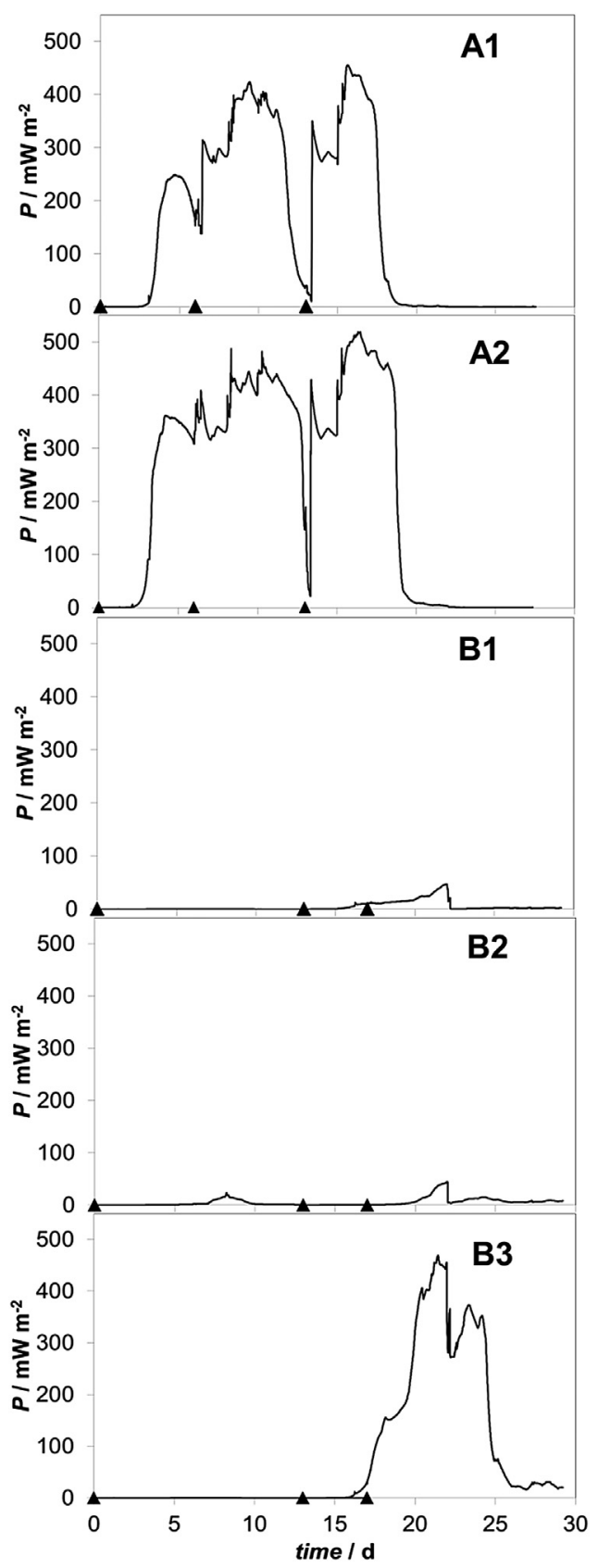

Fig. 5 - Comparison of the power production of the five MFCs. On the $\mathrm{x}$-axis, the additions of the $3 \mathrm{~g} \mathrm{~L}^{-1}$ acetate dose are reported $(\Delta)$.

A significantly different behavior is observed between MFCs equipped with low (A series) and high (B series) Teflon loaded cathodes, but that will be subject of a future paper. Two of the three MFCs with high Teflon ${ }^{\circledR}$ loads were unable to produce any appreciable electron transfer, even if acetate was metabolized (as evidenced by COD measurement not reported here) and a visible biofilm developed. The B3 MFC was able to develop electrogenic biofilms only after 15 days and two more additions of acetate. In all cases of higher Teflon ${ }^{\circledR}$ loads, the generated power was always lower than that for A1 and A2 MFCs.

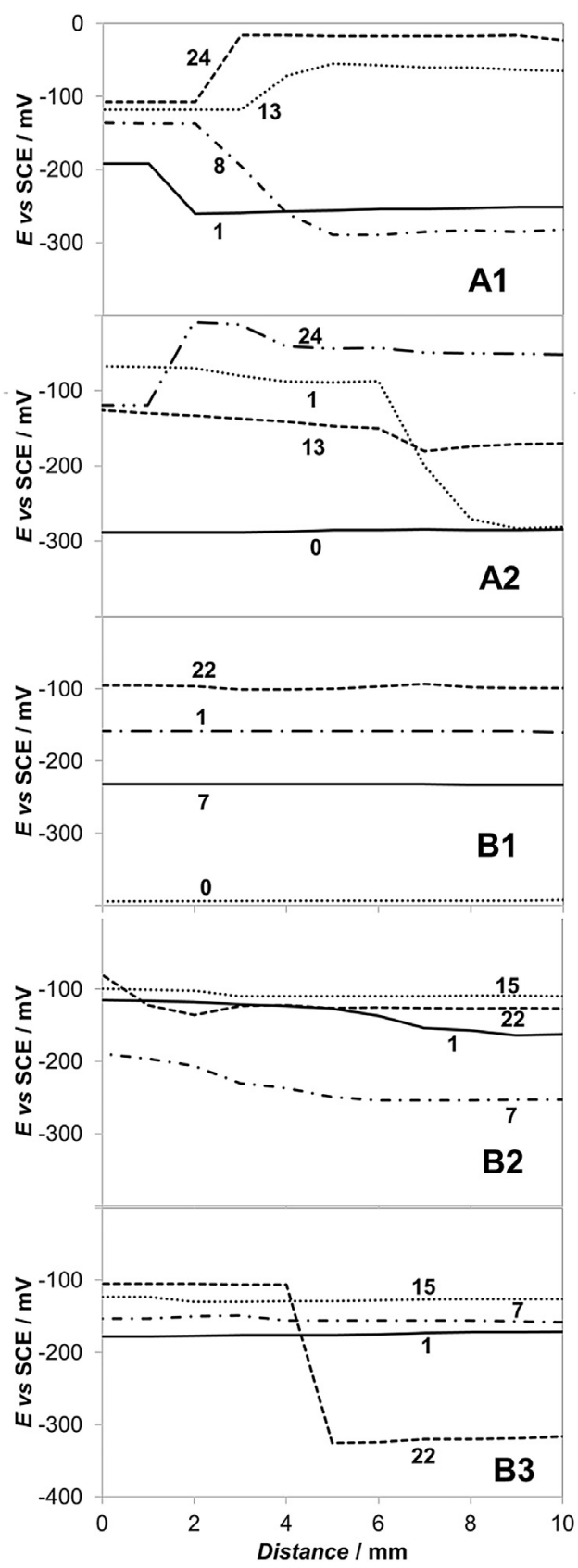

Fig. 6 - Redox profiles and trends of the five MFCs. Numbers on each series refer to the age (days) of the profile recording.

\section{Redox microsensor}

Fig. 6 shows the redox potential trends of the five MFCs. The span of the $X$-axis is set from 0 to $10 \mathrm{~mm}$, because signal variations were found within $10 \mathrm{~mm}$ from the electrode surface. Values at $10 \mathrm{~mm}$ can be taken as representative of the solution bulk. Labels next to each curve represent the number of days at which the redox potential was recorded. A great difference in redox potential is again evident between the $A$ and $B$ series. 
Unproductive MFCs (B1, B2) show flat and practically constant profiles, with no visible difference approaching the cathode surface. The mean value of the redox potential changes with time, becoming generally more positive as acetate is consumed.

Productive MFCs (Fig. 6; A1 and A2) have quite different trends. At start-up, redox profiles are flat and low, but after only one day of operation an increase of the redox potential is observed near the electrode surface. Away from the electrode surface, the redox potential remains unchanged. As the acetate is oxidized, the redox value of the bulk increases, moving upwards from day 13 (just before the addition of the third acetate dose) to day 24. At that point, the depletion of acetate causes a drop in the power production (Fig. 5). Close to the electrode surface, redox potentials increase with time, settling between -200 and $-100 \mathrm{mV}$ (vs. SCE).

In Fig. 6, B3 MFC exhibits flat redox profiles, whose mean value increases with time, as for B1 and B2 MFCs. On day 22, after the 3rd acetate addition, a transition occurs similar to that of A1 and A2 MFCs in the first days. This can be connected to the transition from unproductive to productive MFC (Fig. 5).

Close scrutiny of the Fig. 6, allows to detect significant variations in the redox potential within 2-6 $\mathrm{mm}$ from the cathode surface. This variable distance delimitates two zones with distinct redox behavior: 1) a bulk zone, where acetate depletion governs the redox potential and 2) a zone near the cathode surface, where oxygen depletion plays a fundamental role.

As previously mentioned, the potential of a Pt electrode is determined by electrochemically active redox couples in the solution. At near-neutral $\mathrm{pH}$, the standard redox potential of $\mathrm{O}_{2} / \mathrm{H}_{2} \mathrm{O}$ is ca. $+570 \mathrm{mV}$ (vs. SCE). Oxygen-saturated solutions definitely tend to increase their redox potential, due to the fact that the sensing surface equilibrates slowly with the $\mathrm{O}_{2} / \mathrm{H}_{2} \mathrm{O}$ redox couple. Platinum is not completely reversible towards this couple, so equilibration is somewhat incomplete. As a consequence, the redox potential cannot be used for direct determination of oxygen concentration via the Nernst equation. Sodium acetate oxidation to $\mathrm{CO}_{2}$ has a redox potential close to $-500 \mathrm{mV}$ (vs. SCE, at neutral $\mathrm{pH}$ ). The reaction is kinetically hindered on platinum. Consequently, its contribution to the redox potential is negligible.

This was experimentally confirmed by adding acetate in another productive operating MFC, and monitoring the bulk redox potential as a function of time with a commercial redox sensor (experiment not reported here). As a consequence of acetate addition, the redox potential remained high and unchanged. After a few hours, the redox potential decreased to $-300 \mathrm{mV}$, typical of well-fed productive MFCs. This control experiment demonstrated that low redox potentials are due to redox intermediate couples produced by the metabolism of bacteria degrading acetate, and not by the equilibrium of direct acetate oxidation on Pt.

Redox potential trends can be consequently correlated to the productivity of the MFC that is dependent on oxygen and acetate availability. Near the cathode, the redox potential moves upward with time as the MFC becomes productive, leading to the transformation of the cathode into a biocathode $[17,18]$. Bio-electrocatalysis of oxygen reduction shifts the potential towards the thermodynamic oxygen redox potential. Conversely, a higher concentration of acetate metabolites decreases the redox potential on increasing the distance from the electrode surface.

In Fig. 5, day 24 is in the period of prolonged acetate depletion. On day 24, the redox trends for A1 and A2 MFCs indicate that the bulk value is higher than the value near the cathode. This fact should not be attributed to the presence of oxygen in the bulk solution (the highest oxygen concentration is supposed to be in the proximity of the cathode surface) but to the complete depletion of the reduced form of the redox mediators produced by acetate oxidation.

Power production close to zero in B1 and B2 MFCs is related to the absence of transition of the redox potential near the electrode, as well as a net separation of two zones, where oxygen or acetate biochemistry prevails.

\section{Conductivity microsensor}

Conductivity profiles, collected in each cell on day 8, are reported in Fig. 7. Conductivity is in arbitrary units (a.u.) and only relative variations are discussed. The profiles can be unambiguously attributed to the increase of conductivity as the biofilm develops and the MFC produces power. The increase in conductivity starts at distances less than 3-6 $\mathrm{mm}$ for A1 and A2 MFCs. B1 and B2 do not show relevant changes of conductivity compared with the bulk solution. B3 shows a spike of increased conductivity only at distances less than $1 \mathrm{~mm}$. Bulk conductivity is comparable for all MFCs, proving that the difference in cell productivity is not due to variation of ohmic resistance in the electrolyte bulk. Conversely, the diffusion of species near the electrode is probably hindered as $\mathrm{pH}$ profiles indicate (Fig. 8). As a consequence, a higher concentration of metabolites/ions is produced and/or accumulated inside this zone, with remarkable increase in average conductivity. This mechanism occurs in power producing MFCs only.

However, it should be noted that conductivity measurements may be affected by deformations of the electric field on approaching the cathode. This phenomenon should occur in both productive and unproductive MFCs. Conversely, unproductive MFCs show a flat conductivity profile, demonstrating the irrelevance of this inconvenience.

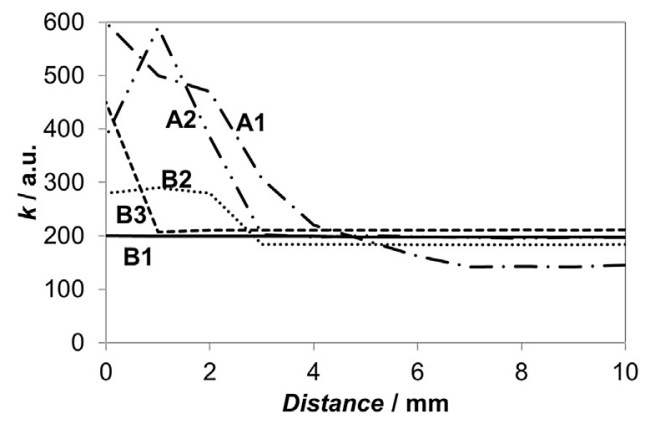

Fig. 7 - Conductivity measurements of the five MFCs. Labels on the series refer to the specific MFC. 


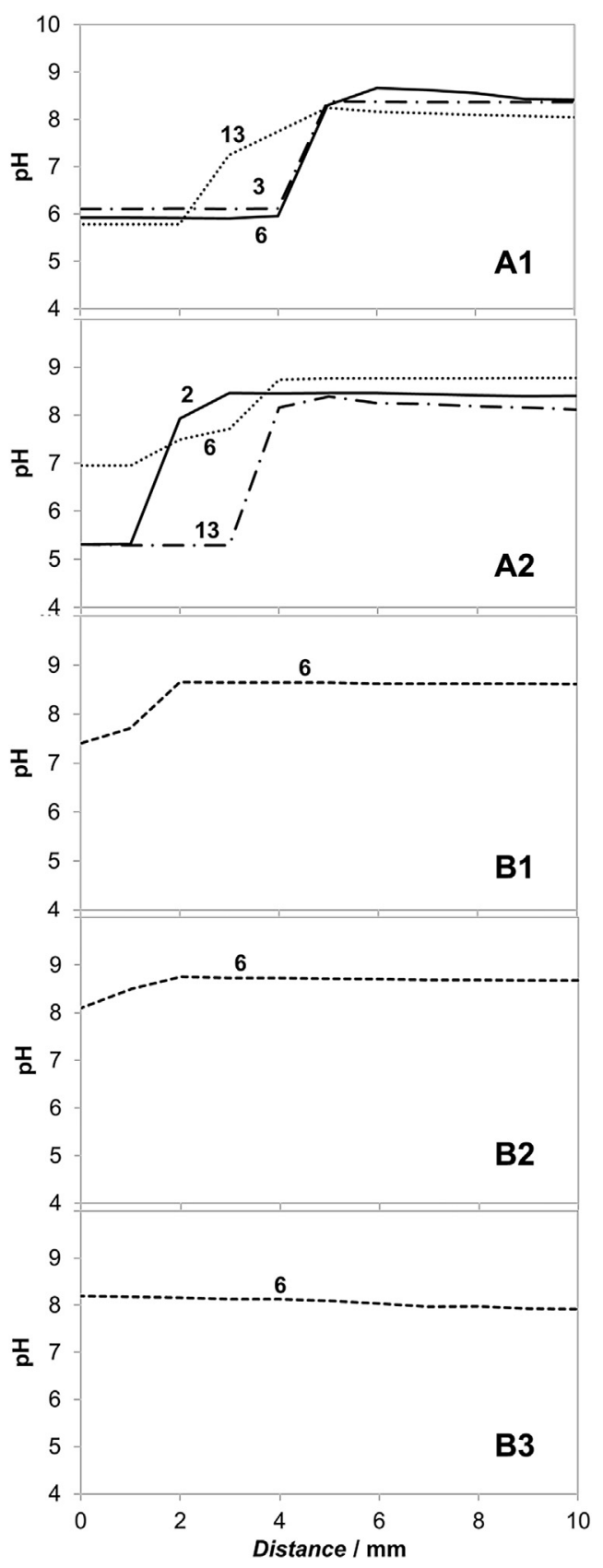

Fig. 8 - pH profiles and trends of the five MFCs. Numbers on each series refer to the age (days) of the profile recording.

\section{pH microsensor}

Fig. 8 shows the $\mathrm{pH}$ profiles of the five MFCs. pH changes are visible for the two MFCs producing power. Diffusion of protons (or other $\mathrm{pH}$-determining species) appears hindered near the electrode surface. As a consequence, dramatic changes in $\mathrm{pH}$ occur as the cathode surface is approached. $\mathrm{pH}$ is approximately 8.5-9 in the bulk, a typical value for the used wastewater. At 3-6 $\mathrm{mm}$ from the cathode surface, $\mathrm{pH}$ drops to neutral or slightly acidic values. Bearing in mind oxygen reduction expected to occur on the cathode:
$\mathrm{O}_{2}+4 \mathrm{e}^{-}+2 \mathrm{H}^{+} \rightarrow 2 \mathrm{OH}^{-}$

it is clear that the recorded $\mathrm{pH}$ variation goes in the opposite direction. This would be understandable if other possible competitive reactions would proceed in the operating MFCs. It was previously reported that chemical or biologically assisted precipitation of carbonates can modify the expected $\mathrm{pH}$ in this type of MFC [25]. XRD analysis conducted on some deposit found in the water-side of the cathode at the end of experiments revealed the presence of this compound.

With respect to unproductive MFCs, no carbonates covered the cathode surface despite acetate depletion, and $\mathrm{CO}_{2}$ was produced by non-electroactive bacteria. All pH profiles were flat, corresponding to the bulk value. $\mathrm{pH}$ microsensors based on $\mathrm{Sb}$ oxides might be sensitive to the solution redox potential. This can be excluded in our work as $\mathrm{pH}$ changes always towards a more acidic environment near the cathode surface. Redox potential instead, varies in a more complex way and changes can be positive or negative. The two measurements represent two uncorrelated variables. This goal was achieved by the application of a coating of Proton exchanging ionomer (Nafion) on the $\mathrm{SbO}_{\mathrm{x}}$ tip of the $\mathrm{pH}$ sensor [23].

\section{Sulphide microsensor}

Sulphide concentration profiles on different days are shown in Fig. 9. The Sulphide concentration is at sub-millimolar level, with variations from cell to cell. As a general rule, higher sulphide concentration in solution corresponds to MFCs with high power production, even after decrease of the power productivity (A1 and A2). A low productivity of the cell is denoted by a lower sulphide concentration (B3). Moreover, the sulphide concentration increases as the cathode surface is approached. Changes in trends may be a reflection of the complex sulphur cycle [18] adopted by the microbial community. Sulphide concentration is thus a balance of production, consumption and chemical redox processes involving sulphur species in the electrode proximity [28]. In all cases, variation of the sulphide concentration is confined to the 3-8 $\mathrm{mm}$ range.

As reported in section 2.2.4., silver sulphide microelectrode showed a calibration line with a more than Nernstian slope. This might indicate an imperfect $\mathrm{Ag}_{2} \mathrm{~S}$ membrane and a

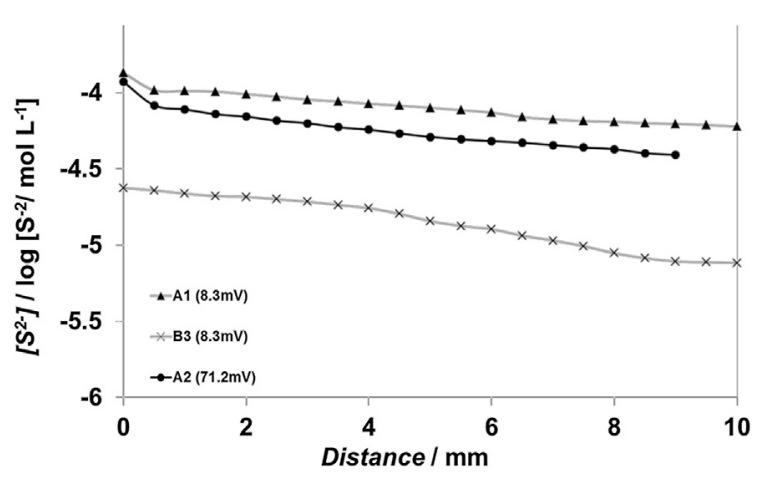

Fig. 9 - Sulphide concentration measurements of the five cells: A1 MFC (A); B3 MFC (x) and A2 MFC (0). 
possible redox interference. However, sulphides increase monotonically near the cathode (Fig. 9), which is not the case of redox trends (Fig. 6).

\section{Microsensor measurements and power production}

As expected, unproductive MFCs generally exhibit flat profiles, with no significant variations of each parameter between the proximity of the cathode surface and the bulk. On the other hand, productive MFCs exhibit parameter variations at a definite distance from the electrode surface. With the utilization of microsensors, this distance was determined to be in the range 3-6 $\mathrm{mm}$ from the cathode surface. Neglecting polarization effects (since microelectrode measurements are made in open-circuit conditions), contribution of microbial metabolic activity inside the biofilm (biocathode) over a discrete and relatively wide volume region close to the electrode surface (3-6 $\mathrm{mm}$ thickness) can be assumed.

Power starts as a thin biofilm is formed on the cathode, and increases with the increase of the biofilm thickness. It is thus reasonable to presume that electron exchange between bacteria and electrode should be catalyzed by external (extracellular) mediators, imposed by the long range interactions needed to cross up to $6 \mathrm{~mm}$ thick biofilm. The measured biofilm in the MFCs are thicker if compared with those reported in the open literature $[30,31]$. However, thicker biofilms were expected, due to the batch and recessed conditions at the cathode surface.

A1 and A2 MFCs, with lower Teflon ${ }^{\circledR}$ content, were more productive in terms of power and exhibited a characteristic profile over time.

Combining the information coming from the four parameters (redox potential, $\mathrm{pH}$, conductivity and sulphides concentration) measured at different times, several conclusions about the behavior of operating Microbial Fuel cells can be put forward.

First, $\mathrm{pH}$ generally decreases near the electrode, showing that the diffusion of $\mathrm{pH}$-determining ions is hindered inside the biofilm as previously demonstrated [29]. Even if oxygen is the final electron acceptor, more complex reactions develop on the biocathode, whose final result is the decrease of $\mathrm{pH}$ [17].

From the recorded sulphide profiles, the difference detected between the concentration inside and outside the biofilm (Fig. 4) confirms a possible role of sulphur compounds in the microbial activity near the cathode.

Conductivity measurements support the finding that biofilms don't cause ohmic drops. On the contrary, they increase the conductivity because of accumulation of chemical species including ions. This statement holds true for early stage biofilms (one month growth) in particular, as the concentration of carbonates and by-products is too low to cause massive biofouling. While biofilms increase conductivity and decrease diffusion, eventual loss in MFC power generation can be due to transport hindrances of reactants and/or products. Diffusional limitation of ions in biofilms could lead to high-surface electrodes producing as much power as lower surface area electrodes, because of the limited interface between biofilm and reagents $[17,29]$.

With respect to redox potential measurements, it is apparent that they could give access to other correlations between biofilm formation and power production, if it is assumed that only oxygen (or its mediators used by the cathodic bacteria) and acetate (or its mediators used by the anodic bacteria) can contribute to the redox potential value. Thus, redox potential profiles estimate the presence of these two groups of redox couples in MFCs. The diffusion-limiting property of biofilms produces two distinct zones: a) the bulk solution, in which redox potential can be decreased by the presence of acetate metabolites (and absence of oxygen), and $b$ ) the cathodic biofilm volume, in which the presence of oxygen (and absence of acetate) moves the redox potential upwards. In the case of A1 and A2 MFCs, the redox potential near the electrode settles to a constant value, demonstrating that oxygen diffusion does not limit the reaction through the entire one-month experiment. Oxygen availability for cathodic biological reactions remains high. Conversely, bulk redox potential moves in accordance with power production, demonstrating the strict connection of these two parameters, both correlated to acetate availability.

\section{Conclusions}

Conventional home made microelectrodes were built-up and used to measure the variation of fundamental physicochemical parameters into biofilms grown on the cathode surface of microbial fuel cells. Redox potential, $\mathrm{pH}$, conductivity and sulphide concentration were measured as a function of both the distance from the cathode surface, and of the duration of the experiment. Microsensors response appears to be strictly correlated with the power density of MFCs.

Sulphide variations inside biofilms confirm a role of the sulphur cycle.

The persistence of a high $\mathrm{pH}$ gradient (between 8.5 and 6) within a few millimeters from the cathode surface, demonstrates diffusion limitations inside the biofilm of productive MFCs.

At the same time, diffusion limitations cause build-up of ions and consequent increase of conductivity inside the biofilm.

The inner part of the biofilm responds to oxygen and ions concentration, while the outer part to acetate metabolites.

Finally, it is possible to estimate the thickness of biofilms by a close analysis of the overall microelectrode responses.

\section{Acknowledgments}

This work was financed by the Research Fund for the Italian Electrical System under the Contract Agreement between RSE and the Ministry of Economic Development - General Directorate for Nuclear Energy, Renewable Energy and Energy Efficiency (July 29, 2009-March 19, 2009). It was partially financed also by the UE grant agreement n. 238579 (FP7th) BIOCOR-ITN. The financial support of the FSE-Lombardia, project number 17157 , is gratefully acknowledged. 


\section{R E F E R E N C E S}

[1] Fornero JJ, Rosenbaum M, Angenent LT. Electric power generation from municipal, food, and animal wastewaters using microbial fuel cells. Electroanal 2010;22:832-43.

[2] Pant D, Van Bogaert G, Diels L, Vanbroekhoven K. A review of the substrates used in microbial fuel cells (MFCs) for sustainable energy production. Biores Tech 2010;101:1533-43.

[3] Wang Z, Ma J, Xu Y, Yu H, Wu Z. Power production from different types of sewage sludge using microbial fuel cells: a comparative study with energetic and microbiological perspectives. J Power Sources 2013;235:280-8.

[4] Lovely DR. Bug juice: harvesting electricity with microorganisms. Nat Rev Microbiol 2006;4:497-508.

[5] Strycharz SM, Malanosky AP, Snider RM, Yi H, Lovley DR, Tender LM. Application of cyclic voltammetry to investigate enhanced catalytic current generation by biofilm-modified anodes of Geobacter sulfurreducens strain DL1 vs. variant strain KN400. Energy Environ Sci 2011;4:896-913.

[6] Satoh H, Mi Odagiri, Ito T, Okabe S. Microbial community structures and in situ sulfate-reducing and sulfur-oxidizing activities in biofilms developed on mortar specimens in a corroded sewer system. Water Res 2009;43:4729-39.

[7] Schreiber F, Loeffler B, Polerecky L, Kuypers MM, de Beer D. Mechanisms of transient nitric oxide and nitrous oxide production in a complex biofilm. ISME $J$ 2009;3:1301-13.

[8] Klimant I, Meyer V, Kuhl M. Fiber-optic oxygen microsensors, a new tool in aquatic biology. Limnology Oceanogr 1995;40:1159-65.

[9] Santegoeds CM, Damgaard LR, Hesselink G, Zopfi J, Lens P, Muyzer G, et al. Distribution of sulfate-reducing and methanogenic bacteria in anaerobic aggregates determined by microsensor and molecular analyses. Appl Environ Microbiol 1999;65:4618-29.

[10] De Beer D, Schramm A. Micro-environments and mass transfer phenomena in biofilms studied with microsensors. Water Sci Tech 1999;39:173-8.

[11] Bocur B. Techinical barriers in the use of electrochemical microsensors and microbiosensors for in vivo analysis of neurological relevant substances. Curr Neuropharmacol 2012;10:197-211.

[12] Cristiani P, Mollica A, Ventura G. On-line monitoring of biofilm and TRO by a new ENEL's system. IEEE OCEANS'98 conference proceedings. vol. 1-3, 1507-11.

[13] Cristiani P. Corrosion monitoring in microbial environments. Techniques for corrosion monitoring, Lietai Yang, editor (SRI, Texas USA), Woodhead publishing limited, CRC press LLC, Cambridge. 2008; 347-87.

[14] Babauta JT, Duc Nguyen H, Beyenal H. Redox and pH microenvironments within Shewanella oneidensis MR1biofilms reveal an electron transfer mechanism. Environ Sci Technol 2011;45:6654-60.
[15] Duc Nguyen H, Renslow R, Babauta J, Ahmed B, Beyenal H. A voltammetric flavin microelectrode for use in biofilms. Sens Actuators B 2012;161:929-37.

[16] Beyenal H, Babauta JT. Microscale gradients and their role in electron-transfer mechanisms in biofilms. Biochem Soc Trans 2012;40:1315-8.

[17] Cristiani P, Franzetti A, Gandolfi I, Guerrini E, Bestetti G. Bacterial DGGE fingerprints of biofilms on electrodes of membraneless microbial fuel cells. Int Biodeter Biodegrad 2013;84:211-9.

[18] Cristiani P, Carvalho ML, Guerrini E, Daghio M, Santoro C, Li B. Cathodic and anodic biofilms in single chamber microbial fuel cells. Bioelectrochemistry 2013;92:6-13.

[19] Santoro C, Lei Y, Li B, Cristiani P. Power generation from wastewater using single chamber microbial fuel cells (MFCs) with platinum-free cathodes and pre-colonized anodes. Biochem Eng J 2012;62:8-16.

[20] Santoro C, Agrios A, Pasaogullari U, Li B. Effects of gas diffusion layer (GDL) and micro porous layer (MPL) on cathode performance in microbial fuel cells (MFCs). Int J Hydrogen Energy 2011;36:13096-104.

[21] Aoki K, Honda K, Tokuda K, Matsuda H. Voltammetry at microcylinder electrodes Part I. Linear sweep voltammetry. J Electroanal Chem 1985;182:267.

[22] Formaro L, Trasatti S. Capacitance measurements on platinum electrodes for the estimation of organic impurities in water. Anal Chem 1968;40:1060-7.

[23] Sisman. Biçer M. Structural, morphological and optical properties of Bi2-xSbxSe3 thin film grown by electrodeposition. J Alloys Comp 2011;509:1538-43.

[24] Vink W. Stability relations of antimony and arsenic compounds in the light of revised and extended Eh-pH diagrams. Chem Geol 1996;130:21-30.

[25] Guerrini E, Cristiani P, Trasatti MSP. Relation of anodic and cathodic performance to $\mathrm{pH}$ variations in membraneless microbial fuel cells. Int J Hydrogen Energy 2013;38:345-53.

[26] Eftekharia A. Chemical sensor based on silver/silver sulfide microelectrode. Anal Lett 2001;34:7.

[27] Ye Y, Huang X, Pan YW, Han CH, Zhao W. In-situ measurement of the dissolved S2- in seafloor diffuse flow system: sensor preparation and calibration. Zhejiang J Univ Sci A 2008;9:423-8.

[28] Santoro C, Cremins M, Mackay A, Pasaogullari U, Guilizzoni M, Casalegno A, et al. Evaluation of water transport and oxygen presence in single chamber microbial fuel cells with carbon-based cathodes. J Electrochem Soc 2013;160:G128-34.

[29] Torres CI, Marcus KA, Rittmann BE. Proton transport inside the biofilm limits electrical current generation by anoderespiring bacteria. Biotech Bioeng 2008;100:872-81.

[30] Read ST, Dutta P, Bond PL, Keller J, Rabaey K. Initial development and structure of biofilms on microbial fuel cell anodes. BMC Microbiol 2010;10:98.

[31] Jones S. Biotechnology: supercharged: the biofilm anode. Nat Rev Microbiol 2008;6:173. 